\title{
Clinical Efficacy and Safety of Acupressure on Low Back Pain: A Systematic Review and Meta-Analysis
}

\author{
Tao Li $\mathbb{D})^{1,2}$ Xiaohui Li $\mathbb{D}^{1,2}$ Fan Huang $\mathbb{D}^{1,2}$ Qiang Tian $\mathbb{D}^{1,2}$ Z. Y. Fan $\mathbb{D}^{1,2}$ and S. Wu $\mathbb{D}^{1,2}$ \\ ${ }^{1}$ The Second Clinical Medical College, Guangzhou University of Chinese Medicine, Guangzhou 510405, Guangdong, China \\ ${ }^{2}$ Massage Department, Guangdong Hospital of Traditional Chinese Medicine, Guangzhou 510405, Guangdong, China \\ Correspondence should be addressed to Z.Y. Fan; fzystrong@163.com and S.Wu; wushan6866@sina.com
}

Received 30 September 2020; Revised 9 January 2021; Accepted 16 February 2021; Published 25 February 2021

Academic Editor: José L. Rios

Copyright (c) 2021 Tao Li et al. This is an open access article distributed under the Creative Commons Attribution License, which permits unrestricted use, distribution, and reproduction in any medium, provided the original work is properly cited.

Objectives. To evaluate the effectiveness and safety of acupressure on low back pain (LBP). Methods. We searched 7 electronic databases and 2 trial registries through December 28, 2020. Randomized controlled trials (RCTs) of acupressure on LBP were considered for meta-analysis with Revman 5.3 and Stata 15.0 software. Methodological quality was evaluated using the Cochrane Collaboration's tool. Trial sequential analysis (TSA) was used to quantify the statistical reliability. HETRED analysis and GRADE were used to determine the heterogeneity and quality of the results, respectively. Results. Twenty-three RCTs representing 2400 participants were included. Acupressure was superior to tuina massage on response rate (RR 1.25; 95\% CI, 1.16 to 1.35 ; $P<0.00001$ ) and in the standardized mean difference (SMD) for pain reduction [SMD $-1.92 ; 95 \% \mathrm{CI},-3.09$ to $-0.76 ; P=0.001$ ] Likewise, acupressure was superior to physical therapy [SMD, $-0.88 ; 95 \% \mathrm{CI},-1.10$ to $-0.65 ; P<0.00001$ ] and to usual care [SMD, $-0.32 ; 95 \% \mathrm{CI},-0.61$ to $-0.02 ; P=0.04]$ in pain reduction. The Oswestry Disability Index was significantly improved by acupressure compared with usual care [SMD, $-0.55 ; 95 \% \mathrm{CI},-0.84$ to $-0.25 ; P=0.0003$ ]. The combination of acupressure with either manual acupuncture or electro-acupuncture showed significant improvements over the adjuvant therapies alone in response rate [RR 1.19; 95\% CI, 1.13 to 1.26; $P<0.00001$ ], pain reduction, and the Japanese Orthopedic Association score (JOA). However, each study displayed substantial heterogeneity. Through subgroup sensitivity analysis and -HETRED analysis, the heterogeneity of acupressure compared with manual acupuncture decreased while the results maintained significance with respect to pain reduction $[\mathrm{SMD}-0.9 ; 95 \% \mathrm{CI},-1.21$ to $-0.6 ; P<0.00001$ ] and JOA [SMD, $0.66 ; 95 \% \mathrm{CI}, 0.33$ to $0.98 ; P<0.00001$ ]. Similar results were obtained comparing acupressure with electro-acupuncture with respect to pain [SMD, $-1.07 ; 95 \% \mathrm{CI},-1.33$ to -0.81 ; $P<0.00001$ ] and JOA [SMD, 0.89; 95\% CI, 0.51 to 1.27, $P<0.00001$. TSA demonstrated the effectiveness of acupressure as a standalone or as a combinative treatment (with manual acupuncture or electro-acupuncture) for LBP. Conclusion. Acupressure is an effective treatment for LBP. However, GRADE assessments downgraded the evidence in the trials, indicating that additional investigations are needed to confirm these observations.

\section{Introduction}

Low back pain (LBP) affects 540 million people worldwide and is the leading cause of disability [1]. The number of years lived with LBP has increased by $54 \%$ between 1990 and 2015 at all income levels and age groups worldwide [1]. In the USA, annual healthcare costs of LBP are estimated to be $\$ 100$ billion, imposing an economic burden on the healthcare system [2]. An underlying cause for LBP has not been identified for most patients. However, several pathological causes have been identified for some patients such as intervertebral disc damage, vertebral fracture, tumors, infection, and physical and mental comorbidities [3]. Many therapeutic options are currently recommended for LBP, but the emphasis is now on complementary medicine such as exercise and physical therapy rather than on pharmacological and surgical treatments [4].

In traditional Chinese medicine (TCM), LBP is closely associated with the obstruction of the meridians and collaterals of the lower back, which start at the head, descending parallel to the midline and the lateral of the back, and end in the feet. The treatment is based on dredging the obtrusion of 
these meridians [5]. Acupressure on the meridians and collaterals is a noninvasive and straightforward technique, embracing the principle of Yin and Yang and the close relationship between Qi and blood circulation [6]. Acupressure from fingers, palms, or elbows on the appropriate acupoints helps promote the circulation of Qi and blood in the meridians of the lower back, relaxing muscles, and alleviating LBP [7]. Previous studies have suggested that acupressure may increase the production of endogenous sedatives and analgesics by the stimulation of the autonomic nervous system [8]. The efficacy of acupressure on LBP has been assessed in several meta-analyses. However, these reviews discussed the effectiveness of auricular acupressure on LBP based on limited researches or the acupressure treatments from nontherapists or the use of instrumentation [9-11]. We performed this analysis because of the absence of a meta-analysis on the therapeutic effects and safety of traditional acupressure on the effectiveness of traditional acupressure treatment of LBP.

\section{Methods}

2.1. Registration. The review was registered with the International Prospective Register of Systematic Reviews (PROSPERO) database (registration number: CRD42020144586).

2.2. Data Source and Search Strategy. The meta-analysis and systematic review were conducted following the Preferred Reporting Items for Systematic Reviews and Meta-Analysis (PRISMA) statement [12]. Literature searches were conducted through the following electronic databases from their inception to November 25, 2019: PubMed; Embase; the Cochrane Central Register of Controlled Trials (CENTRAL); Clinicaltrials.gov; the Chinese Scientific Journal Database (VIP); Wan-fang Data; the Chinese Biomedical Literature database (CBM); the China National Knowledge Infrastructure (CNKI); and the Chinese Clinical Trial Registry (ChiCTR). We searched MeSH term trees for "acupressure" and "low back pain" in PubMed, and the keywords searched included "acupressure", "shiatsu", "zhi ya", "low back pain", "lumbago", "low back ache", and "randomized controlled trial". The above keywords were translated into Chinese and searched in the abovementioned Chinese databases as well. Search terms were combined with the Boolean "AND" and "OR" terms in search strategies, e.g., "acupressure" OR "shiatsu" OR "zhi ya") AND ("low back pain" OR "lumbago" OR "low back ache") AND ("randomized controlled trial" (Table 1 in the Supplement). Selected studies and reviews were screened for relevant trials. Journal editors and experts in the relevant fields were consulted for additional study sources. Finally, Open Grey was searched for qualifying studies.

\subsection{Inclusion Criteria}

2.3.1. Types of Study. Randomized control trials (RCTs) that evaluated the effectiveness of acupressure on LBP were included. No restrictions were set on publication type, language, or status.
2.3.2. Types of Participants. Patients ( $\geq 18$ years old) who were diagnosed with LBP were eligible for inclusion without any restriction on sex, nationality, race, the period or nature of prior treatments, past or existing diseases, economic status, or inpatient or outpatient care.

2.3.3. Types of Interventions. For interventions, acupressure only or adjunctive treatments, such as usual care, sham acupressure, acupuncture, or physical therapy, combined with acupressure was applied in the test group.

For control groups, usual care, sham acupressure, acupuncture, or physical therapy could be applied in the control group. If acupressure was applied with adjunctive treatments, the identical adjunctive treatment should be applied in the control groups as well.

2.3.4. Types of Outcome Evaluations. Response rate, pain intensity, and functional ability were used as primary outcomes to evaluate the effectiveness of acupressure compared to other treatments. Response rate is defined as the proportion of participants who reported relief from pain or symptoms. Pain intensity was measured by the Visual Analogue Scale (VAS). Since VAS has either $0-10 \mathrm{~cm}$ or $0-100 \mathrm{~mm}$ range, the values are normalized up to a $0-10 \mathrm{~cm}$ range for comparability. For functional ability, we used the Oswestry disability index (ODI) and Japanese Orthopedic Association scores (JOA). The JOA has either 0-17 or 0-29 scores, and all 0-17 scales are normalized to 0-29 scores for comparability.

Adverse events during treatments and the usage count of each acupoint selected in the articles were analyzed as secondary outcomes.

2.4. Exclusion Criteria. Studies applying auricular acupressure or acupressure on specific reflexology areas of the hands or feet were excluded to study the effectiveness of acupressure on the meridians and collaterals of the body. Investigations in which acupressure was undertaken by therapeutic devices or non-medical staff were excluded as well.

2.5. Data Extraction. Data extraction was completed in duplicate and independently by two reviewers (TL and XL). Specific characteristics were extracted: author; publication year; sample size; the detail of the intervention and comparison; frequency; duration of treatments; follow-up intervals; and outcomes. We contacted the authors of the studies twice over six weeks via e-mail for missing or unclear data. If no response was received, the data were marked as unclear. A third reviewer (QT) assisted for consensus when disagreement occurred.

2.6. Assessment of Quality and the Level of Evidence. Methodological quality was assessed with the Cochrane Collaboration's tool for assessing risks of bias from 7 domains: random sequence generation; blinding of patients; 
allocation concealment; selective reporting; incomplete outcome data; and other biases [13]. Each of these domains was rated as low, high, or unclear risk. Each study was classified at one of three levels: low, high, or unclear risk of bias based on the overall risk assessments of the 7 domains. The quality of the body of evidence for the different outcomes was assessed with the GRADE approach (GRADE pro, Version 3.6 for Windows, Grade Working group) [14].

2.7. Statistical Analysis. We analyzed all outcomes with Stata 15.0 (Stata Corp, College Station, TX, USA). Studies were arranged according to the outcome measures and the type of intervention (acupressure monotherapy or in combination with acupuncture). Pooled dichotomous outcomes were presented as risk ratios (RRs) and 95\% confidence intervals (CIs) while pooled continuous outcomes were presented as weight mean differences (WMDs) with $95 \%$ CIs or standardized mean differences (SMDs) with 95\% CIs when using multiple measurements. The fixed-effect model was applied if heterogeneity was not significant $\left(I^{2} \leq 50 \%\right.$ or $P \geq 0.10$ in the $Q$ test). Otherwise, subgroup analysis was performed to identify the source(s) of the heterogeneity. Planned subgroup analyses included the types of adjunctive interventions (manual acupuncture or electro-acupuncture) and the duration of treatments ( $\leq 2$ weeks or $>2$ weeks). Sensitivity analysis and HETRED analysis were conducted to further identify the trials resulting in significant heterogeneity [15]. If the source(s) of the heterogeneity was still unidentifiable, a random effect model was utilized for data synthesis.

2.7.1. Publication Bias. Publication bias was assessed using funnel plots and Egger's test quantitatively when at least 10 trials were included. Significant publication bias was considered when $P<0.05$.

2.7.2. Trial Sequential Analysis. Trial sequential analysis (TSA) was conducted to detect the robustness of the results of the meta-analysis by calculating the required information size (RIS) with TSA 0.9.5.5 software (Copenhagen Trial Unit, Centre for Clinical Intervention Research, Rigshospitalet, Copenhagen, Denmark) [16]. We took the sample size as RIS. The required indexes for TSA were type I error $(\alpha=0.05)$ and type II error $(\beta=0.2)$.

\section{Results}

3.1. Literature Search Results. The Preferred Reporting Items for Systematic Reviews and Meta-analyses (PRISMA) flow diagram (Figure 1) shows the entire review process from the original search to the final selection of studies. Twenty-three studies [8,17-38] with a total of 2400 participants were included. The characteristics of the included RCTs are presented in Table 1.

3.2. Characteristics of Interventions and Controls. Table 1 summarizes the characteristics of 23 RCTs in this analysis. In seven studies $[20,23,28,33,34,36,38]$, acupressure was compared with tuina massage (TM). In these studies, acupressure was distinguished from TM by the methods recorded, and no acupressure techniques were involved in TM in the control group. In three studies $[18,19,26]$, acupressure was compared with physical therapy (PT). In two of these trials $[18,19]$, sample size, patient characteristics, and evaluation of outcomes differed but otherwise used similar research designs and interventions. This indicated that these studies were not duplicates. In seven studies, acupressure combined with electro-acupuncture was compared to electroacupuncture alone [21, 25, 29-32, 37]. In four studies, acupressure combined with manual acupuncture was compared to manual acupuncture alone $[22,24,27,35]$. In two of these studies $[24,31]$, the frequency and duration of the acupressure treatments differed between trials. In two studies [8, 17], acupressure was compared with usual care (UC), which included conventional medication or health education. In 17 studies $[8,20-23,25-27,29,30,32-38]$, acupressure was performed at least once a day. In three studies [31, 35, 37], acupressure combined with acupuncture was performed once every other day. In two studies $[17,28]$, acupressure was performed once a week. The duration of treatment periods among trials ranged from 2 weeks to 5 weeks (Table 1).

3.2.1. LBP Outcomes. Response rates were measured in 17 studies [20-30, 32-38]. Values for JOA, VAS, and ODI were determined in 7 studies [21, 22, 24, 25, 30, 35, 39], 14 studies $[18,19,21,22,24-28,30,33,34,38]$, and 2 studies $[8,17]$, respectively. Since other outcomes, such as Roland and Morris disability questionnaire, fatigue severity scale, McGill pain questionnaire, straight leg raising test, or functional independence measurement, were separately applied in one of the included studies, they cannot be pooled and analyzed.

3.3. Quality Assessment. Most of the 23 included studies reported proper random sequence generations (Figure 2(a)). There were 3 studies $[23,32,37]$ that did not meet this requirement and were rated as having a high risk of bias for allocating patients according to their date of admission or clinic record number. There were 17 studies $[20-27,29-35,37,38]$ investigating the effectiveness of acupressure that (1) did not report an appropriate method for allocation concealment, (2) did not provide clear instructions for blinding of participants or personnel, or (3) lacked study protocols or available trial registration records (Figure 2(a)). These studies were also rated as having an unclear risk bias of selective reporting because of a lack of study protocols or available trial registration records. Only three studies [17-19] performed intention-to-treat analyses. All 23 studies were rated as having a low risk of attrition bias for incomplete outcome data (Figure 2(a)). Based on these results, the overall assessment of risks of bias was rated (Figure 2(b)). Three studies were classified at high risk of bias $[23,32,37]$ while 5 studies $[8,17-19,28]$ was with low risk of bias. The other 15 studies [20-22, 24-27, 29-31, 33-36, 38] were rated with unclear risk of bias. 


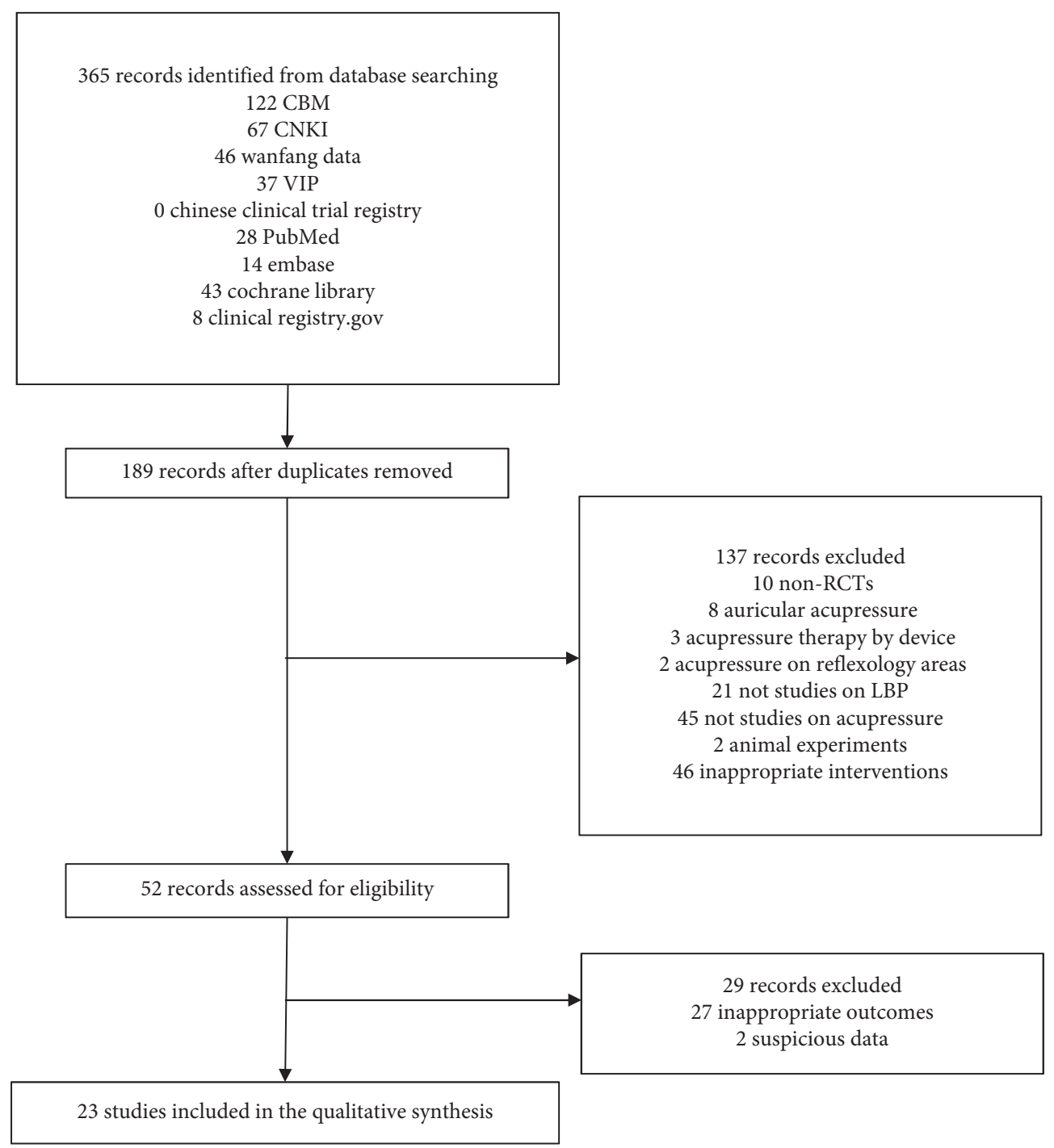

FIGURE 1: PRISMA flow diagram.

\subsection{Meta-Analysis}

3.4.1. Response Rate. Seven studies [20, 23, 28, 33, 34, 36, 38] examined the response rate of acupressure on LBP compared with tuina massage. The meta-analysis assessed by a fixedeffect model revealed a significant difference in the shortterm response rate, however with marked heterogeneity $\left(I^{2}=72 \%\right)$. Sensitivity analysis and HETRED analysis were undertaken (Figure 3). After removing the data of Lu et al. [38], Zhang [34], and Zheng et al. [33], the $I^{2}$ value decreased from $72 \%$ to $0 \%$. The pooled result in the fixed model (Figure 4(a)) was still in favor of acupressure $[R R=1.25 ; 95 \%$ CI, 1.16 to $1.35, P<0.0001$; heterogeneity, $\left.I^{2}=0 \%, P=0.96\right]$.

Nine studies [21, 22, 25, 27, 29, 30, 32, 35, 37] reported a response rate the combinative therapy of acupressure with acupuncture in comparison with acupuncture alone. We found a significant difference in the short-term response rate with low heterogeneity $[\mathrm{RR}=1.19 ; 95 \% \mathrm{CI}$, 1.13 to $1.26 ; P<0.0001$; heterogeneity, $\left.I^{2}=0 \% ; P=0.58\right]$ (Figure 4(b)).
3.4.2. Pain Intensity. Three studies $[18,19,26]$ compared the pain reduction of acupressure versus physical therapy at one month. There was evidence of significant pain relief using acupressure $[\mathrm{SMD}=-0.88 ; 95 \% \mathrm{CI},-1.110$ to -0.65 ; $P<0.0001$; heterogeneity, $I^{2}=29 \% ; P=0.25$ ] (Figure 5(a)).

Pooled results from two studies $[8,17]$ indicated that acupressure generated significant improvement on LBP compared to UC $[\mathrm{SMD}=-0.32 ; 95 \% \mathrm{CI},-0.61$ to -0.02 ; $P=0.04$; heterogeneity, $I^{2}=26 \% ; P=0.25$ ] (Figure 5(b)).

Four studies $[28,33,34,38]$ assessed the analgesic effect of acupressure compared with tuina massage. The pooled data suggested a greater pain reduction, although with substantial heterogeneity $\left(I^{2}=97 \%\right)$. Owing to the similar clinical characteristics in these studies, we were unable to perform subgroup analysis. Sensitivity and HETRED analysis detected no potential source of heterogeneity. After confirming the data accuracy with the studies' authors, we adopted the random effect model and the subsequent analysis demonstrated favorable effects of acupressure [SMD,$-1.92 ; 95 \% \mathrm{CI},-3.09$ to $-0.76 ; P=0.001$ ] (Figure 6). 
TABLE 1: Characteristics of the included studies.

\begin{tabular}{|c|c|c|c|c|c|c|c|}
\hline Study & $\begin{array}{l}\text { Sample size } \\
(\mathrm{T} / \mathrm{C})\end{array}$ & $\begin{array}{c}\text { Age (years; SD) } \\
\text { (T/C) }\end{array}$ & $\begin{array}{l}\text { Intervention } \\
(\mathrm{T} / \mathrm{C})\end{array}$ & Frequency & $\begin{array}{l}\text { Treatment } \\
\text { duration }\end{array}$ & $\begin{array}{l}\text { Follow-up } \\
\text { interval }\end{array}$ & Outcome \\
\hline $\begin{array}{l}\text { Hsieh et al. } 2004 \\
\text { [18] }\end{array}$ & $69 / 77$ & $\begin{array}{l}47.6 \pm 13.6 / \\
47.6 \pm 14.9\end{array}$ & $\mathrm{~A} / \mathrm{PT}$ & Unclear & 1 month & 6 months & (2) (6) (8) \\
\hline $\begin{array}{l}\text { Hsieh et al. } 2006 \\
\text { [19] }\end{array}$ & $64 / 65$ & $\begin{array}{c}50.2 \pm 13.8 / \\
52.6 \pm 17.2\end{array}$ & $\mathrm{~A} / \mathrm{PT}$ & Unclear & 1 month & 6 months & (3) (6) \\
\hline $\begin{array}{l}\text { Zhang et al. } 2017 \\
{[26]}\end{array}$ & $30 / 30$ & 18 to 55 & $\mathrm{~A} / \mathrm{PT}$ & QD & 1 month & NM & (1) (5) (6) \\
\hline Wen 2015 [28] & $64 / 59$ & $\begin{array}{l}52.72 \pm 9.27 / \\
49.09 \pm 14.31\end{array}$ & $\mathrm{~A} / \mathrm{TM}$ & QW & 5 weeks & NM & (1) (6) \\
\hline $\begin{array}{l}\text { Zheng et al. } 2012 \\
\text { [33] }\end{array}$ & $90 / 90$ & $45.6 / 46.2$ & $\mathrm{~A} / \mathrm{TM}$ & $\begin{array}{l}\text { QD } 5 \text { times/ } \\
\text { week }\end{array}$ & 20 days & 1 year & (1)(5) (6) \\
\hline Lu et al. 2004 [38] & $54 / 50$ & $\begin{array}{c}47.0 \pm 10.41 / \\
45.0 \pm 11.01\end{array}$ & $\mathrm{~A} / \mathrm{TM}$ & QD & 20 days & NM & (1) (6) \\
\hline Wang 2010 [36] & $44 / 40$ & $43.5 \pm 10.5 / 42.8 \pm 9.7$ & $\mathrm{~A} / \mathrm{TM}$ & QD & 10 days & NM & (1) \\
\hline Liao et al. 2018 [23] & $100 / 100$ & $\begin{array}{c}38.26 \pm 7.65 / \\
38.37 \pm 7.35\end{array}$ & $\mathrm{~A} / \mathrm{TM}$ & QD & 2 weeks & NM & (1) (10) \\
\hline $\begin{array}{l}\text { Zhang et al. } 2018 \\
{[20]}\end{array}$ & $42 / 42$ & $\begin{array}{c}43.63 \pm 3.23 / \\
42.95 \pm 3.54\end{array}$ & $\mathrm{~A} / \mathrm{TM}$ & QD & 1 month & NM & (1) (11) \\
\hline Zhang 2010 [34] & $131 / 130$ & $\begin{array}{c}43.36 \pm 11.43 / \\
41.84 \pm 11.62\end{array}$ & $\mathrm{~A} / \mathrm{TM}$ & QD & 20 days & NM & (1) (6) \\
\hline Huo 2009 [37] & $25 / 25$ & $48.5 / 47.7$ & $\mathrm{~A}+\mathrm{EA} / \mathrm{EA}$ & QOD & 24 days & NM & (1) (6) \\
\hline $\begin{array}{l}\text { Liu and Guo } 2014 \\
\text { [30] }\end{array}$ & $30 / 30$ & $44.15 / 46.23$ & $\mathrm{~A}+\mathrm{EA} / \mathrm{EA}$ & $\begin{array}{l}\text { QD } 5 \text { times/ } \\
\text { week }\end{array}$ & 2 weeks & NM & (1) (5) \\
\hline Hu 2015 [29] & $40 / 40$ & $40.2 \pm 3.8 / 39.6 \pm 3.5$ & $\mathrm{~A}+\mathrm{EA} / \mathrm{EA}$ & QD & 2 weeks & NM & (1) \\
\hline Bei 2018 [25] & $40 / 40$ & $\begin{array}{l}27.73 \pm 3.51 / \\
28.16 \pm 3.49\end{array}$ & $\mathrm{~A}+\mathrm{EA} / \mathrm{EA}$ & $\begin{array}{l}\text { QD } 5 \text { times/ } \\
\text { week }\end{array}$ & 2 weeks & NM & (1) (6) \\
\hline $\begin{array}{l}\text { Zhang and Zhao } \\
2018[21]\end{array}$ & $60 / 60$ & $\begin{array}{l}48.55 \pm 10.28 / \\
48.58 \pm 10.26\end{array}$ & $\mathrm{~A}+\mathrm{EA} / \mathrm{EA}$ & $\begin{array}{l}\text { QD } 6 \text { times/ } \\
\text { week }\end{array}$ & 3 weeks & NM & (1) (5) (6) \\
\hline Hua et al. 2014 [31] & $30 / 30$ & $\begin{array}{c}39.53 \pm 9.66 / \\
41.93 \pm 9.71\end{array}$ & $\mathrm{~A}+\mathrm{EA} / \mathrm{EA}$ & QOD & 10 days & NM & (6) \\
\hline Su 2013 [32] & $30 / 39$ & $\begin{array}{l}52.87 \pm 8.86 / \\
48.86 \pm 11.24\end{array}$ & $\mathrm{~A}+\mathrm{EA} / \mathrm{EA}$ & $\begin{array}{l}\text { QD } 6 \text { times/ } \\
\text { week }\end{array}$ & 2 weeks & NM & (1) (4) (8) \\
\hline Tan 2017 [27] & $60 / 60$ & $49.3 \pm 8.5 / 50.1 \pm 7.9$ & $\mathrm{~A}+\mathrm{MA} / \mathrm{MA}$ & QD & 20 days & NM & (1)(4)(6) \\
\hline $\begin{array}{l}\text { Hua and Wang } 2018 \\
\text { [24] }\end{array}$ & $30 / 30$ & $43.6 \pm 10.4 / 40.9 \pm 9.7$ & $\mathrm{~A}+\mathrm{MA} / \mathrm{MA}$ & QOD & 10 days & NM & (5) (6) \\
\hline $\begin{array}{l}\text { Zeng and Pei } \\
2018 \text { [22] }\end{array}$ & $45 / 45$ & $\begin{array}{l}38.05 \pm 6.21 / \\
37.56 \pm 5.68\end{array}$ & $\mathrm{~A}+\mathrm{MA} / \mathrm{MA}$ & $\begin{array}{l}\text { QD } 6 \text { times/ } \\
\text { week }\end{array}$ & 2 weeks & NM & (1) (5) (6) \\
\hline Lin 2010 [35] & $30 / 30$ & $\begin{array}{c}43.9 \pm 9.922 / \\
44.6 \pm 8.315\end{array}$ & $\mathrm{~A}+\mathrm{MA} / \mathrm{MA}$ & QOD & 10 days & NM & (1) (5) \\
\hline $\begin{array}{l}\text { Kobayashi et al. } \\
2019 \text { [17] }\end{array}$ & $27 / 24$ & $67.4 \pm 12.2 / 68.3 \pm 15$ & $\mathrm{~A} / \mathrm{UC}$ & QW & 1 month & 1 month & (3) (4) (6) (8) \\
\hline Chen 2015 [8] & $65 / 64$ & $\begin{array}{c}18.75 \pm 1.74 / \\
18.73 \pm 0.63 \\
\end{array}$ & $\mathrm{~A} / \mathrm{UC}$ & BID & 1 week & $\begin{array}{c}4 \\
\text { months }\end{array}$ & (4) (6) \\
\hline
\end{tabular}

Note: (1). A: acupressure; PT: physical therapy; TM: tuina massage; EA: electro-acupuncture; MA: manual acupuncture; UC: usual care. (2). Outcome indicator: (1) response rate; (2) Short-Form Pain Questionnaires; (3) Roland and Morris Disability Questionnaire; (4) Oswestry Disability Index; (5) Japanese Orthopedic Association Score; (6) Visual Analogue Scale; (7) Fatigue Severity Scale; (8) Short-Form McGill Pain Questionnaire; TCM Syndrome Index; (9) straight leg raise; (10) functional independence measurement; (3). BID: twice a day; QD: once a day; QOD: once every other day; QW: once a week; NM: not mentioned.

Six studies $[21,22,24,25,30,35]$ reported the effect of combination therapy of acupressure and acupuncture compared with acupuncture alone on pain intensity. Less pain intensity was indicated when using the combined treatment of acupressure and acupuncture [SMD, -1.13 ; $95 \% \mathrm{CI},-1.31$ to $-0.94 ; P<0.00001]$. However, since significant heterogeneity existed among these trials $\left(I^{2}=68 \%\right)$, a subgroup analysis was performed (Table 2$)$. In the subgroup, the pooled result favored the combinative therapy of acupressure and electro-acupuncture with low heterogeneity [SMD, $-1.07 ; 95 \% \mathrm{CI},-1.33$ to
$-0.81 ; \quad P<0.00001 ; \quad$ heterogeneity, $\left.I^{2}=0 \% ; \quad P=0.37\right]$ (Figure $8(\mathrm{a})$ ). In the subgroup for acupressure with manual acupuncture, the heterogeneity remained considerable (85\%). Sensitivity and HETRED analyses were therefore performed (Figure 7). After removing the study from Zeng and Zhao [21], the $I^{2}$ value decreased ( $85 \%$ to $2 \%$ ) (Figure 8(b)). The subgroup analysis showed the combination of acupressure with manual acupuncture generated superior analgesic effects to the control group [SMD, $-0.9 ; 95 \% \mathrm{CI},-1.21$ to $-0.6 ; \quad P<0.00001$ ]. (Figure 8(b)). 


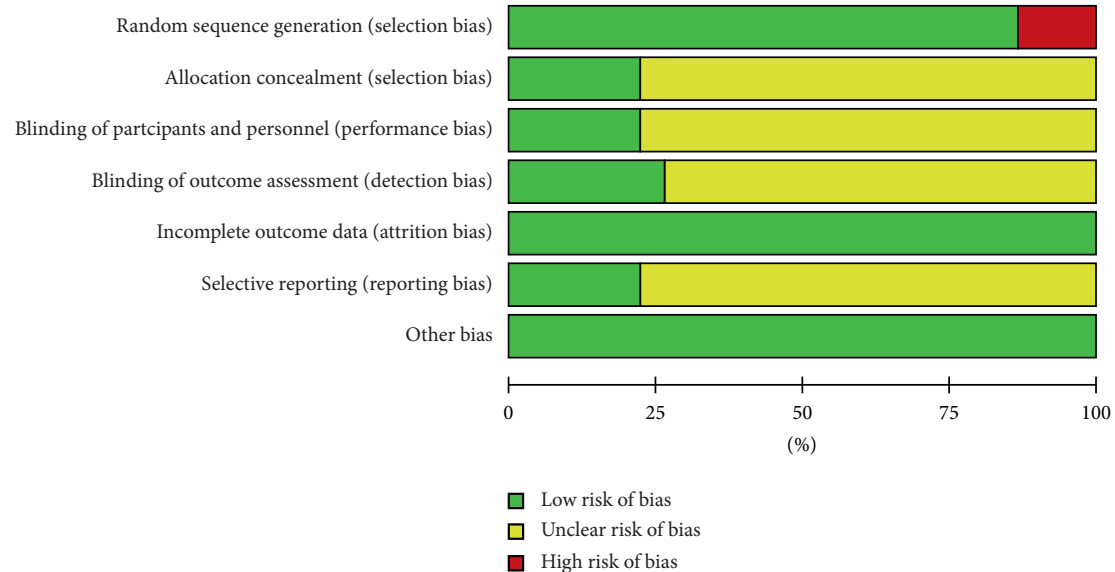

(a)

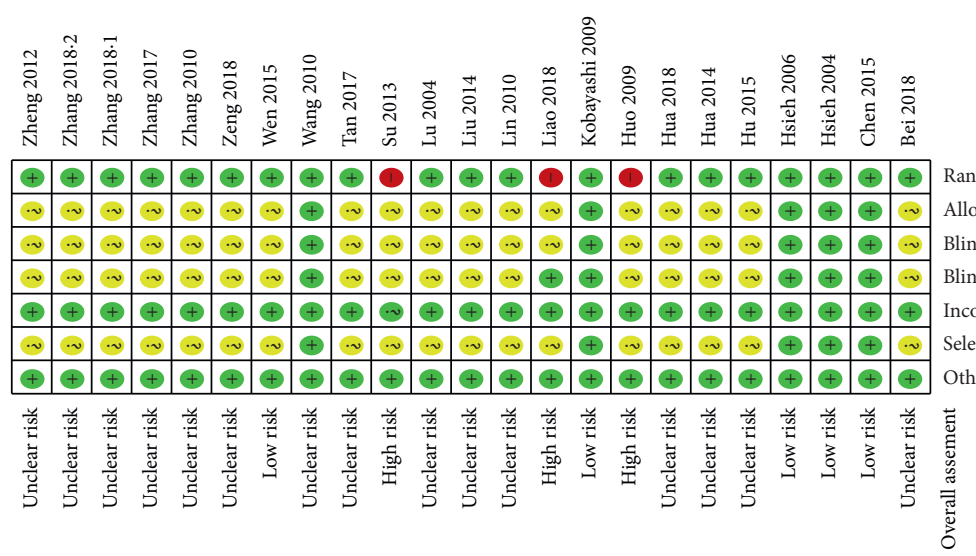

(b)

Figure 2: Risk of bias and summary.

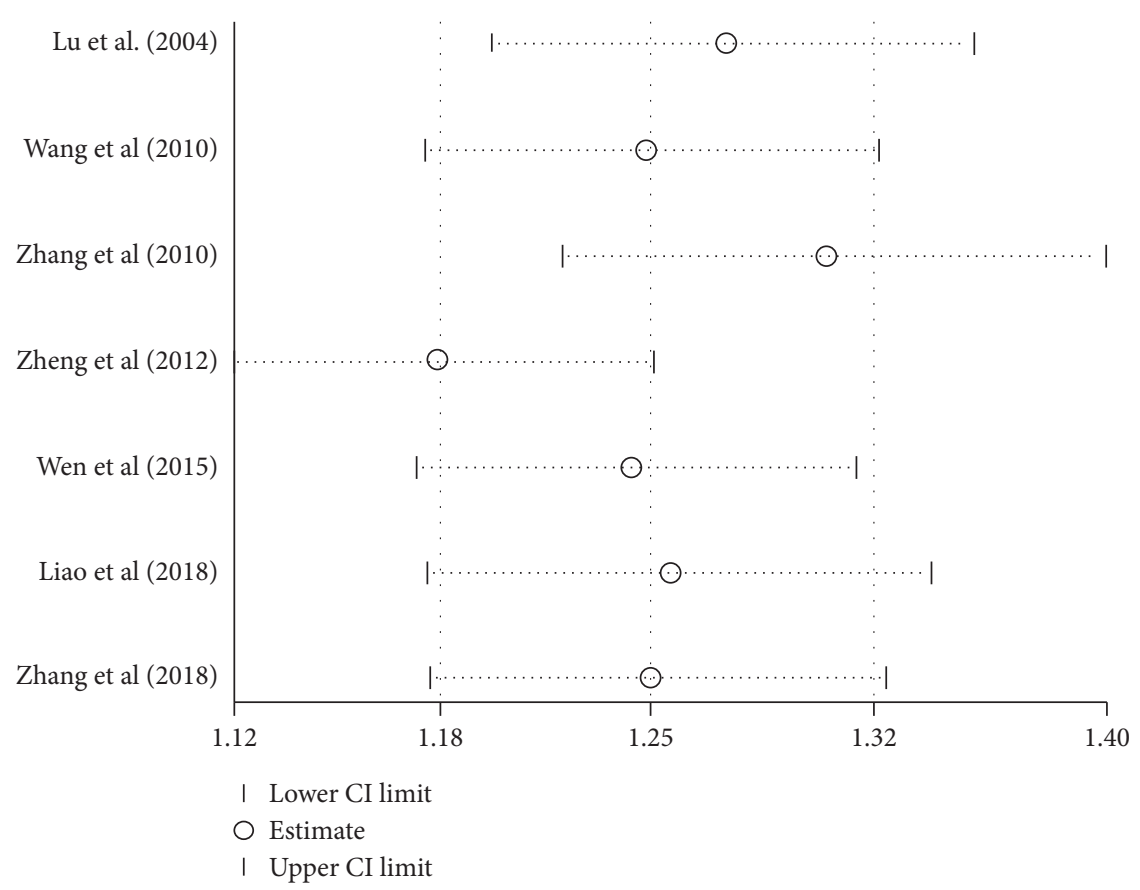

FIGURE 3: Sensitivity analysis of response rate of acupressure versus tuina massage. 


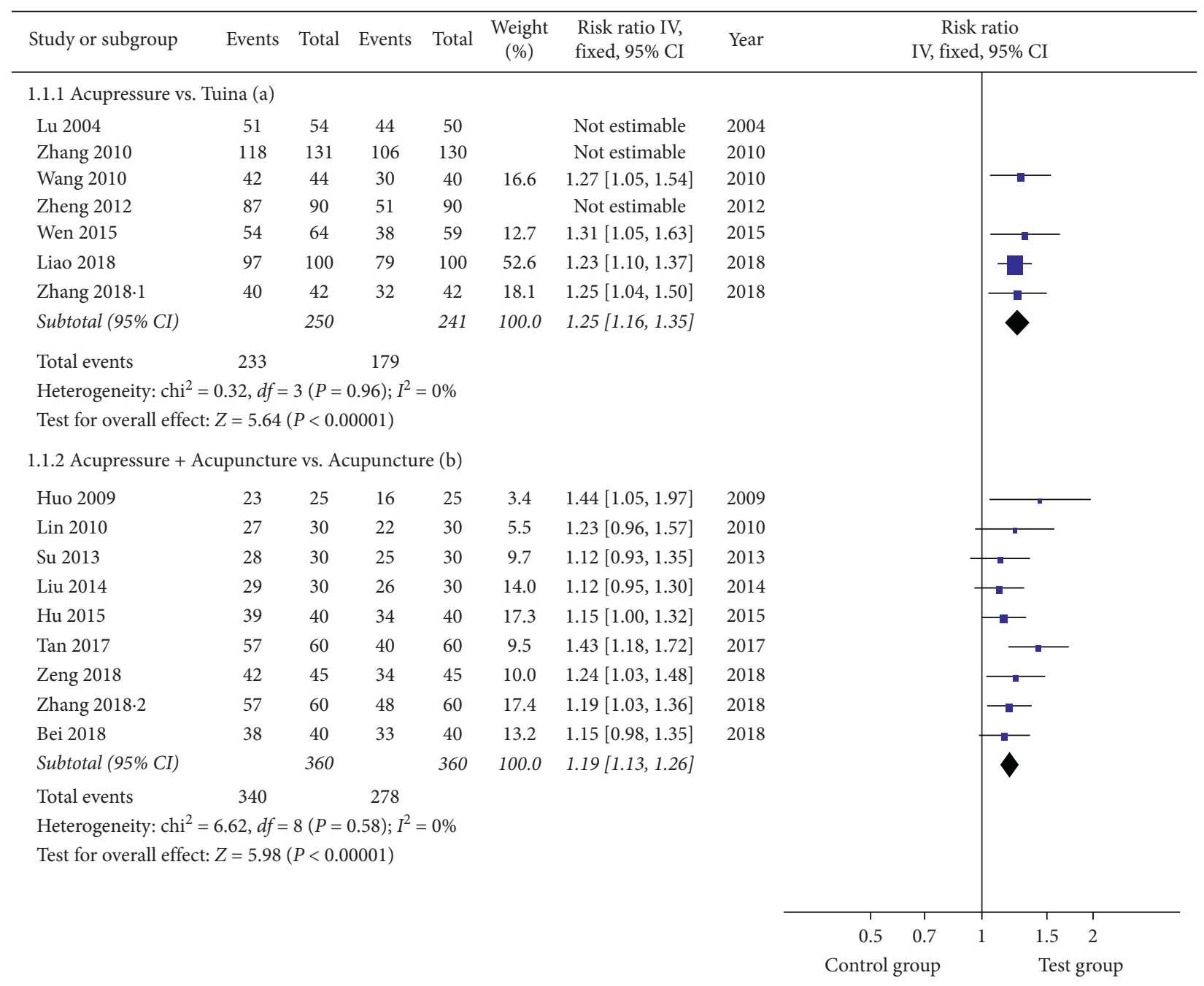

FIGURE 4: Forest plot of the response rates of acupressure versus tuina and acupressure + acupuncture versus acupuncture.

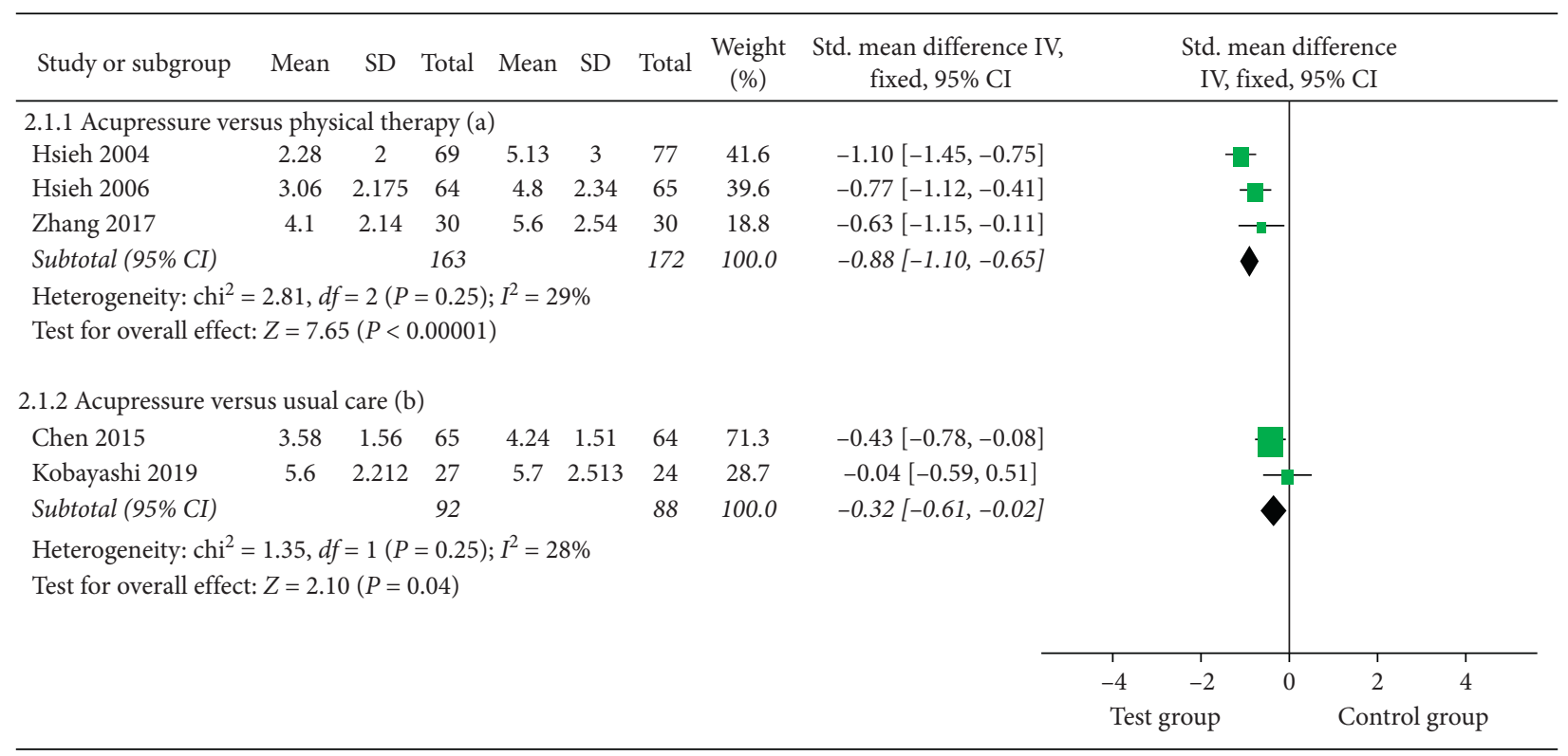

FIGURE 5: Forest plot of the pain intensity of acupressure versus physical therapy and acupressure versus usual care. 


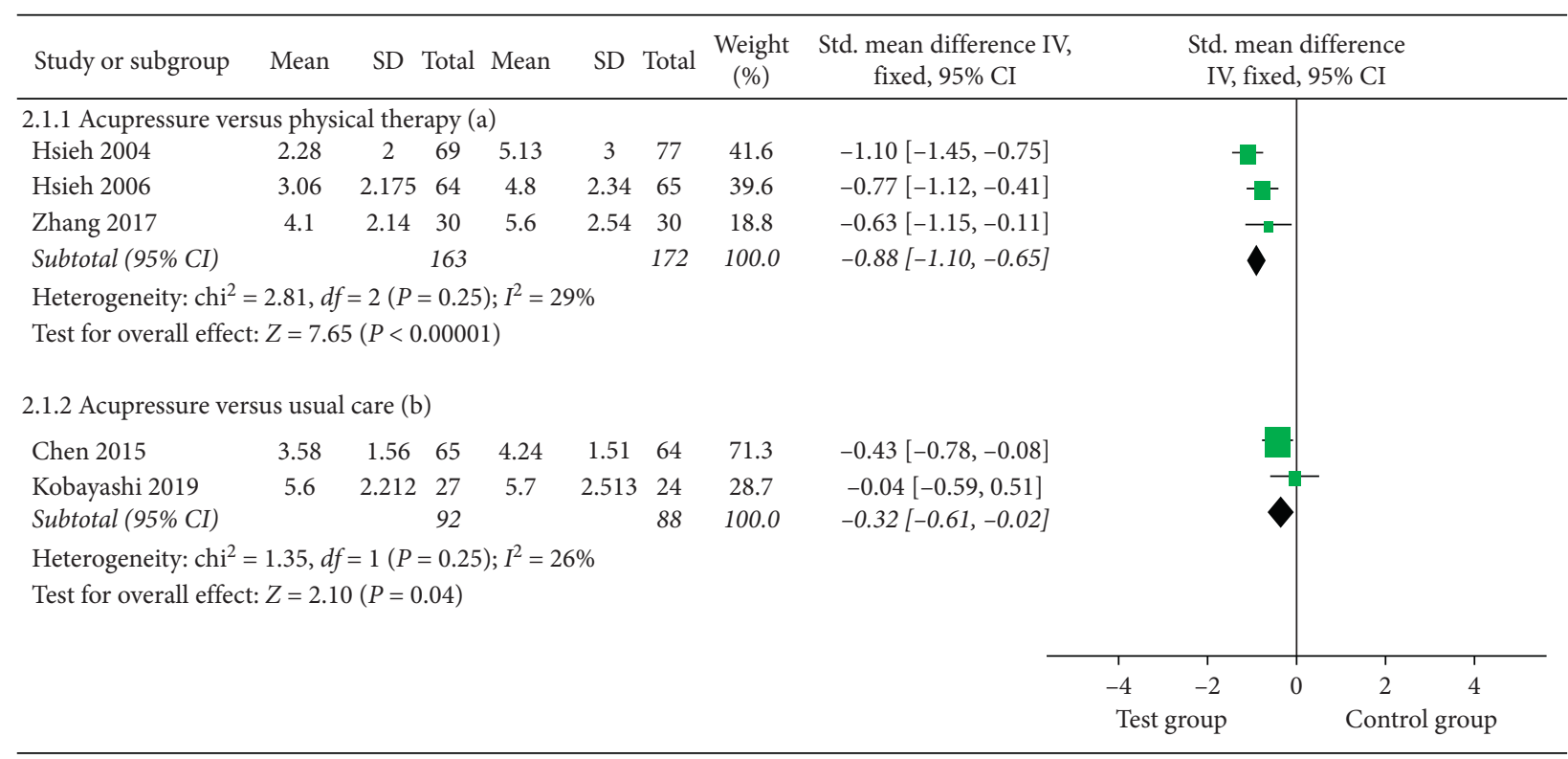

FIGURE 6: Forest plot of pain intensity of acupressure versus tuina massage.

TABLE 2: Subgroup analyses of the combination therapy of acupressure with acupuncture.

\begin{tabular}{|c|c|c|c|c|c|}
\hline \multirow{2}{*}{ Characteristic } & \multirow{2}{*}{ Patients } & \multirow{2}{*}{ Studies } & \multirow{2}{*}{ Fixed-effects SMD $(95 \% \mathrm{CI})$} & \multicolumn{2}{|c|}{ Heterogeneity } \\
\hline & & & & $I^{2}$ & $P$ \\
\hline \multicolumn{6}{|l|}{ Pain intensity } \\
\hline \multicolumn{6}{|l|}{ Duration of treatments } \\
\hline$\leq 2$ weeks & 410 & 5 & $-1.16(-1.37,-0.95)$ & $74 \%$ & 0.004 \\
\hline$>2$ weeks & 120 & 1 & $-1.02(-1.40,-0.64)$ & - & - \\
\hline \multicolumn{6}{|l|}{ Adjunctive interventions } \\
\hline Manual acupuncture & 270 & 3 & $-1.19(-1.45,-0.92)$ & $85 \%$ & 0.001 \\
\hline Electro-acupuncture & 260 & 3 & $-1.07(-1.33,-0.81)$ & $0 \%$ & 0.37 \\
\hline \multicolumn{6}{|l|}{ JOA } \\
\hline \multicolumn{6}{|l|}{ Duration of treatments } \\
\hline$\leq 2$ weeks & 410 & 5 & $1.22(1.0,1.43)$ & $94.9 \%$ & $<0.00001$ \\
\hline$>2$ weeks & 60 & 1 & $0.72(0.20,1.24)$ & - & - \\
\hline \multicolumn{6}{|l|}{ Adjunctive interventions } \\
\hline Manual acupuncture & 150 & 2 & $0.66(0.33,0.98)$ & $0.0 \%$ & 0.7 \\
\hline Electro-acupuncture & 320 & 4 & $1.43(1.18,1.68)$ & $83.0 \%$ & 0.0006 \\
\hline
\end{tabular}

3.4.3. Japanese Orthopedic Association Score (JOA). The effects of acupressure plus acupuncture compared to acupuncture on LBP using JOA in 6 studies $[21,22,24,25,30,35]$ were examined. Because substantial heterogeneity was found in these studies $\left(I^{2}=84 \%\right)$, we performed a subgroup analysis based on the duration of treatments or types of adjunctive interventions (Table 2). In the subgroup for the combination of acupressure with manual acupuncture, the pooled data in fixed model demonstrated a significant increase of JOA scores [SMD, 0.66 ; $95 \% \mathrm{CI}, 0.33$ to 0.98$) ; P<0.0001$; heterogeneity, $\left.I^{2}=0 \% ; P=0.70\right]$ (Table 2 and Figure $9(\mathrm{~b})$ ). In the subgroup of acupressure with electro-acupuncture compared with electro-acupuncture alone, the heterogeneity was still considerable $\left(I^{2}=83 \%\right)$. The following sensitivity and HETRED analysis indicated that the inclusion of two studies [21, 25] might be the cause of the high heterogeneity (Figure 10). After removing these studies from the analysis, the pooled results in the fixed model showed a significant improvement in the test group [SMD, 0.89, 95\% CI, 0.51 to $1.27 ; P<0.00001$; heterogeneity, $I^{2}=0 \%$; $P=0.36]$ (Figure 9(a)).

3.4.4. Oswestry Disability Index (ODI). Two studies [8, 17] examined the effects of acupressure versus usual care on LBP using ODI. The pooled data suggested a significant improvement associated with acupressure compared with usual care [SMD, $-0.55 ; 95 \% \mathrm{CI},-0.84$ to $-0.25 ; \quad P=0.0003 ;$ heterogeneity, $\left.I^{2}=0 \% ; \quad P=0.50\right]$ (Figure 11).

3.4.5. Adverse Events. Adverse events reported in studies were sparse. Six studies $[17,19,22,32,33,35]$ mentioned the term "adverse reactions" of which 4 studies $[19,22,33,35]$ only descriptively reported that no 


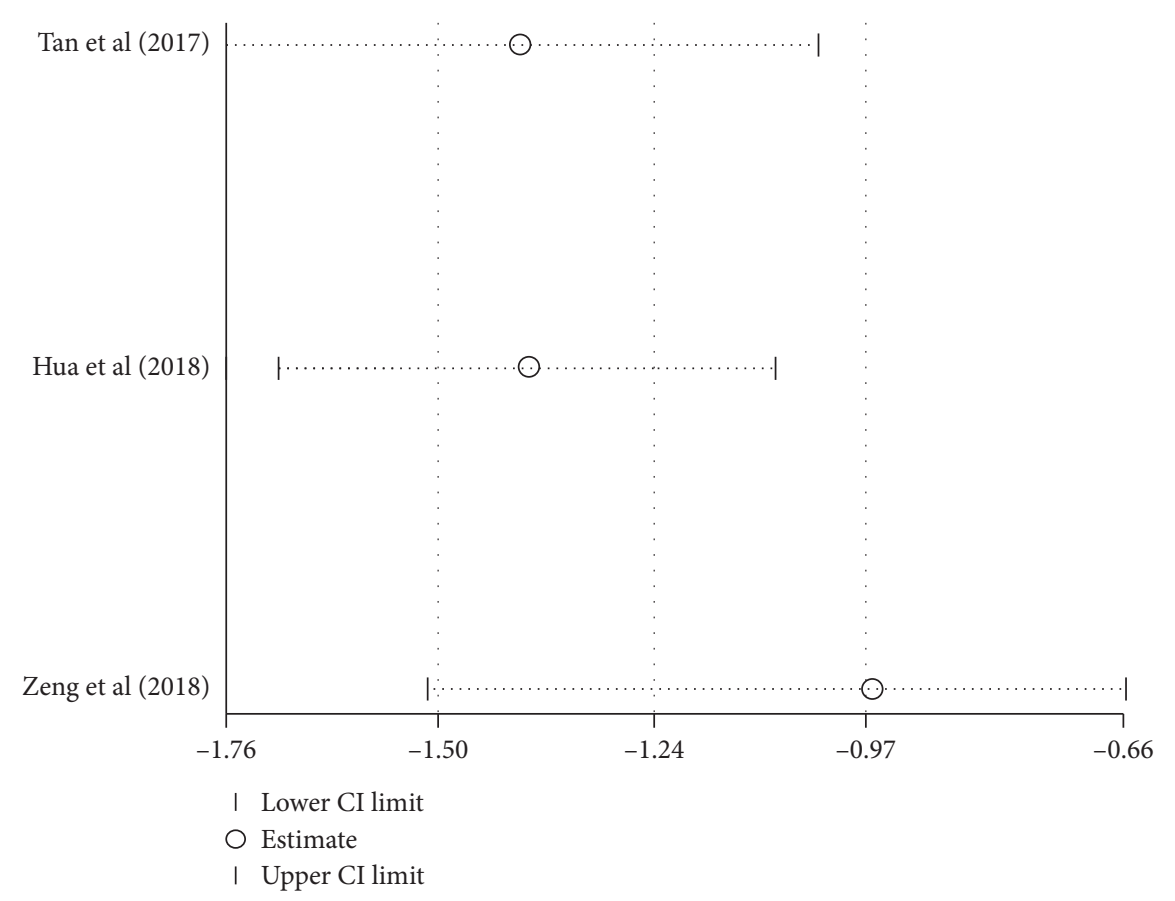

FIGURE 7: Sensitivity analysis of pain intensity of acupressure combined with manual acupuncture versus manual acupuncture.

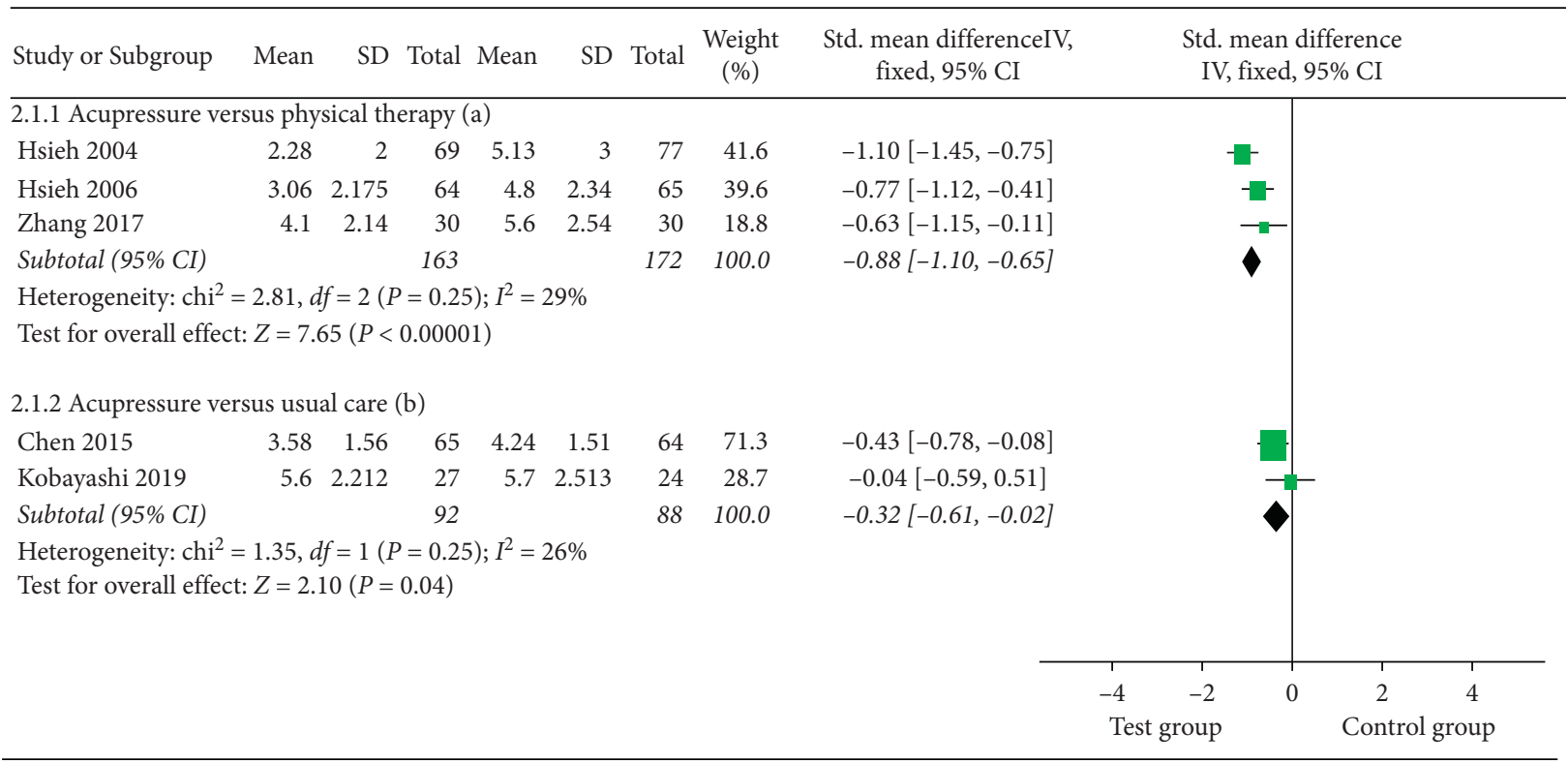

FIGURE 8: Forest plot of the pain intensity of acupressure combined with electro-acupuncture versus electro-acupuncture and acupressure combined with manual acupuncture versus manual acupuncture.

adverse reaction occurred in either the test or control groups. Two studies $[17,32]$ reported the total number of the symptoms and the solutions to adverse events. The incidence of adverse reactions was $0.42 \%(5 / 1200)$ in the test groups compared with $0.25 \%(3 / 1200)$ in the control groups. The primary adverse reactions observed in the treatment group included muscle pain or headache while those in the control group included dizziness, urticaria, and abdominal pain. The adverse events of the two groups were tolerable and did not require specific interventions.
3.4.6. Usage Counts of the Acupoints. The usage counts of each acupoint selected for treatment were calculated. The most frequently-used acupoints were Weizhong (BL40), Huantiao (GB30), Chengshan (BL57), Dachangshu (BL25), Ashi points, Yanglingquan (GB34), Kunlun (BL60), Zhibiao (BL54), Yinmen (BL37), and Shenshu (BL23) (Figure 12).

3.4.7. Trial Sequential Analysis (TSA). TSA was undertaken with the data from 2 meta-analyses. A TSA on the comparison of the response rate of acupressure with that of tuina 


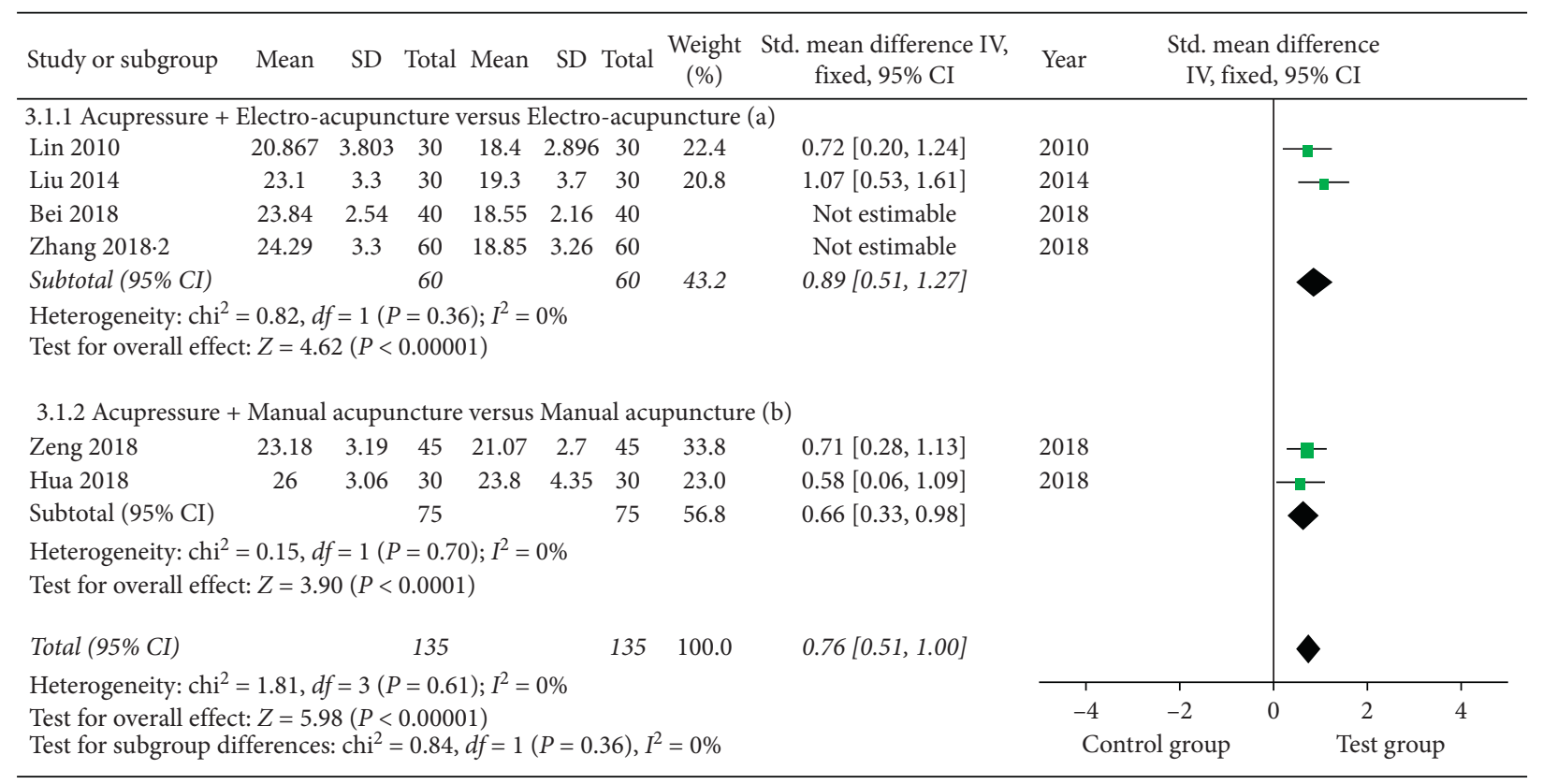

Figure 9: Forest plot of JOA.

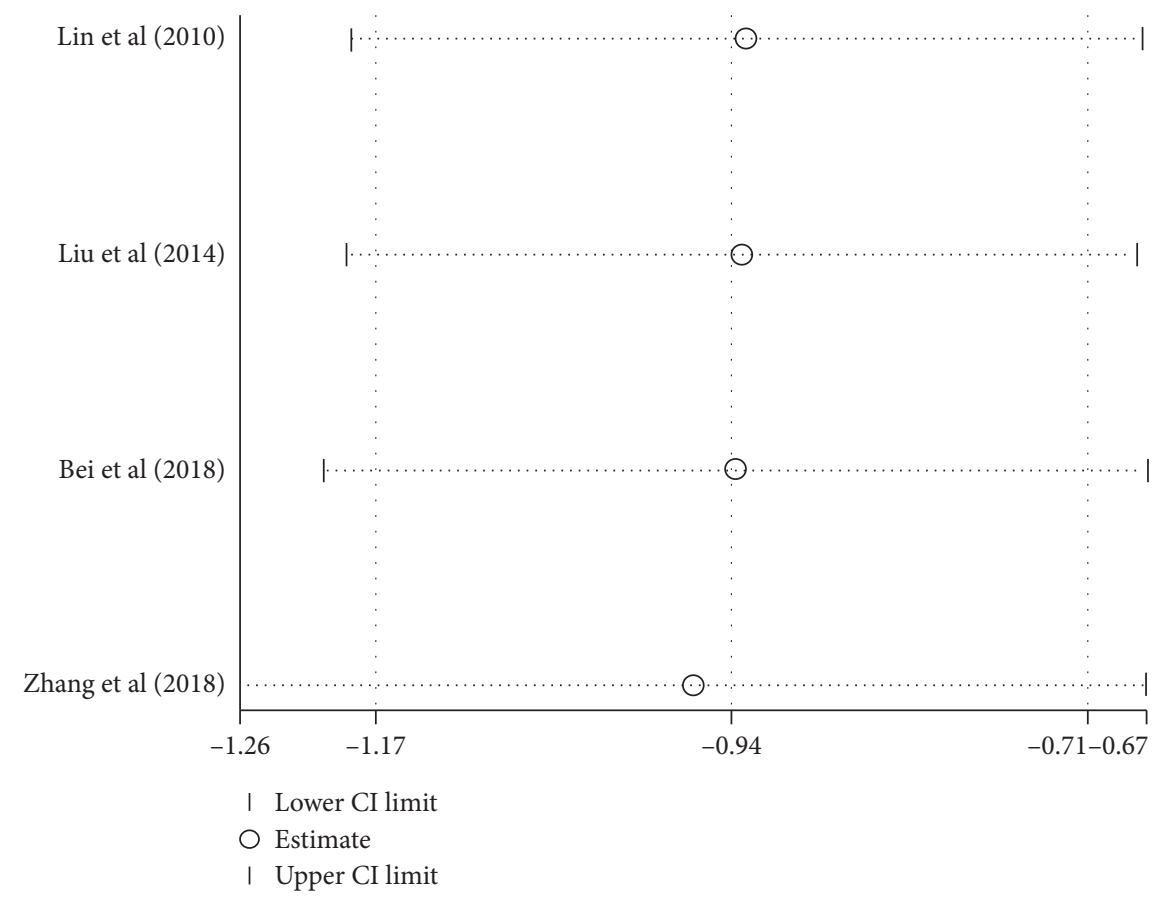

FIGURE 10: Sensitivity analysis of JOA: acupressure combined with electro-acupuncture versus electro-acupuncture.

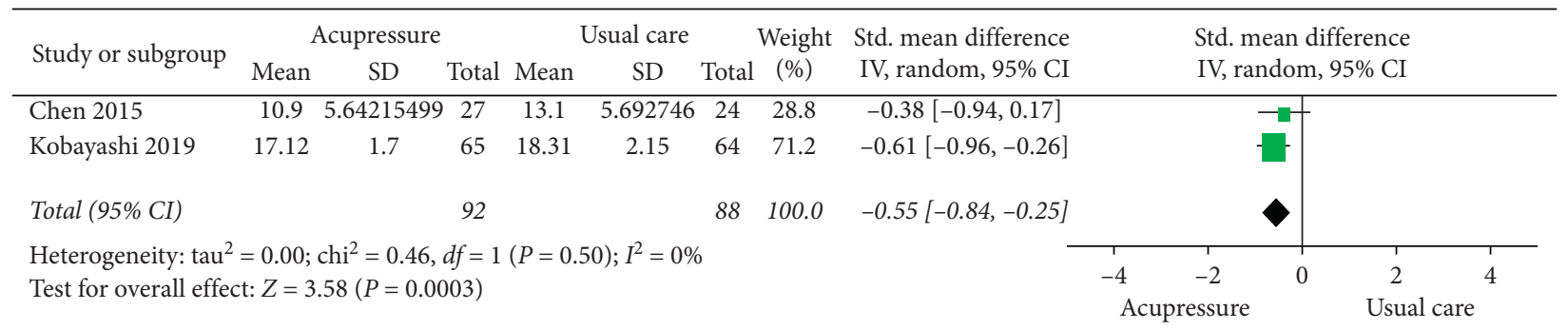

FIGURE 11: Forest plot of ODI. 


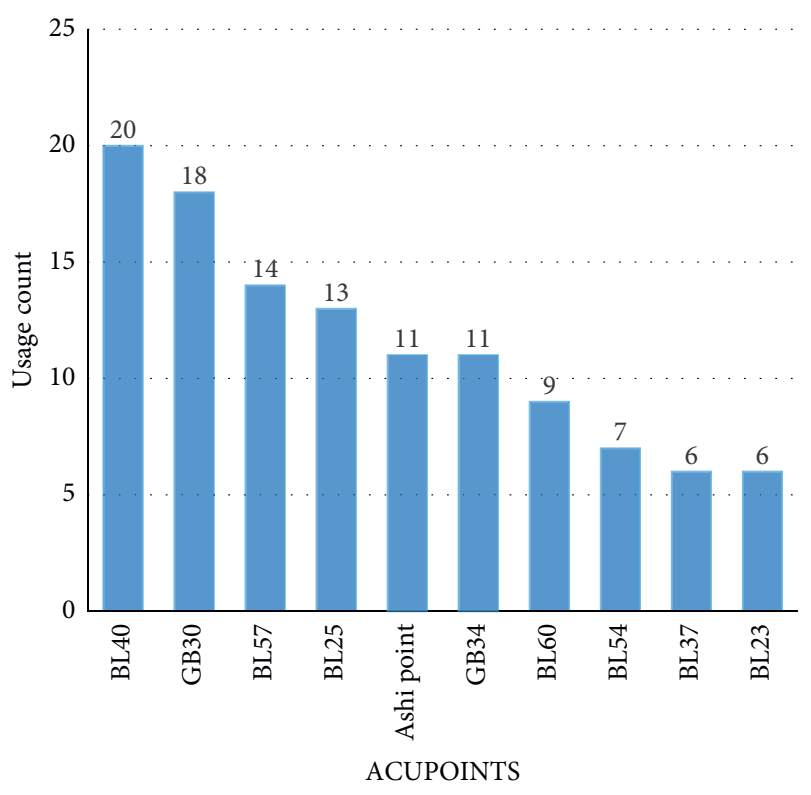

Figure 12: Comparison of acupoint use.

massage revealed that the cumulative $Z$-curve crossed the traditional boundary of $5 \%$ significance (horizontal line) and the monitoring boundaries (inward sloping curves) (Figure 13(a)). After the inclusion of Wang 2010, the significance of $5 \%$ was reached every time a new trial was added to the meta-analysis. The results support the conclusion that acupressure improves the response rate over that of tuina massage with $\mathrm{RR}=1.25$.

In the comparison between acupressure plus acupuncture versus acupuncture, TSA revealed that the cumulative $Z$-curve crossed the traditional boundary of $5 \%$ significance and the monitoring boundaries (Figure 13(b)), indicating that the sample size achieved the required 150 participants and confirmed that the combinative treatment could improve the response rate on $\operatorname{LBP}(\mathrm{RR}=1.19)$.

3.4.8. GRADE. The grade of the evidence obtained for the response rate using JOA, VAS, or ODI for acupressure was low or very-low (Table 3 ). These results were similar to the grade of evidence for the combinative treatment of acupressure and acupuncture. Only the trials comparing acupressure with physical therapy provided moderate-grade evidence (Table 3 ).

The reasons for downgrading the evidence were the poor methodological quality, high heterogeneity, wide confidence intervals, and insufficient sample size among relevant trials. Wide confidence intervals and small sample sizes also contributed to the downgrading of the evidence. No serious indirectness was identified. The summary of findings and evidence profile is presented in Table 3.

\section{Discussions}

The systematic review and meta-analysis included 23 RCTs with 2400 participants with LBP. Consistent with previous systematic reviews [6, 40], moderate-quality evidence revealed an association between acupressure and greater pain relief compared with physical therapy. Although rated as very-low to low, poor quality evidence suggested that acupressure, with or without combinative acupuncture therapy, contributed to a greater amelioration of pain and functional disability from LBP compared with usual care, tuina massage, or acupuncture. TSA results revealed that adequate studies supported the significance of the clinical response rate of acupressure, with or without combinative acupuncture therapy, compared to other treatments.

Although positive results suggesting acupressure as a standalone or as a combinative treatment for LBP, highquality evidence was insufficient to make an informed decision. The methodological limitations of the included RCTs may have impacted the accuracy and reliability of the evidence. Owing to the complex and variable characteristics of therapies like acupressure, acupuncture, and massage, most studies used a nonblinded pragmatic trial to study the efficacy of the therapies, which may have increased their performance bias. Rigorous research methods, such as sham-controlled double-blinded designs, are necessary to minimize bias in evaluating the effectiveness of acupressure. Most outcome measures were dependent on patient-reported scales or questionnaires (JOA, ODI, and VAS), which are vulnerable to the subjective conditions of the patient and/or assessor. Physiological outcome indicators, including the range of motion, pain threshold, and muscle tone in the lower back, are encouraged to be included in future planned research protocols. Only 3 RCTs conducted mid-to-longterm follow-up indicating that the long-term efficacy of acupressure remains to be considered.

The most frequently-used acupoints were located on the bladder and the gallbladder meridians. In TCM theory, these acupoints are closely correlated with the liver and kidney, which govern the function of bone and tendon. Acupressure over these points could promote the $Q i$ and blood circulation of these specific meridians to improve the body's ability to recover the proper functions of muscles, tendons, and bones in the lower back [19]. Modern medical studies have suggested stimulation of acupoints could enable the production of endogenous opioids (endorphin) and certain peptides, which act as both analgesics and sedatives and alleviate LBP [41-43].

When acupressure was compared solely or as an adjunctive with acupuncture, substantial heterogeneity was found among the study's results. We conducted subgroup analyses on the duration of treatment and adjunctive interventions and found that adjunctive interventions might be contributing to the heterogeneity. However, considerable heterogeneity remained unexplained in the pooled results. In the comparison between acupressure and Tuina massage on pain intensity, the heterogeneity was substantial and unexplained. Acupressure is sometimes considered a subapplication of tuina massage since both are noninvasive techniques. However, the locations of interventions and operational techniques between the two forms are different. Tuina massage includes different techniques such as rolling, pushing, shaking, kneading, scrubbing, or stretching. We speculate that details of the tuina techniques, such as types, 


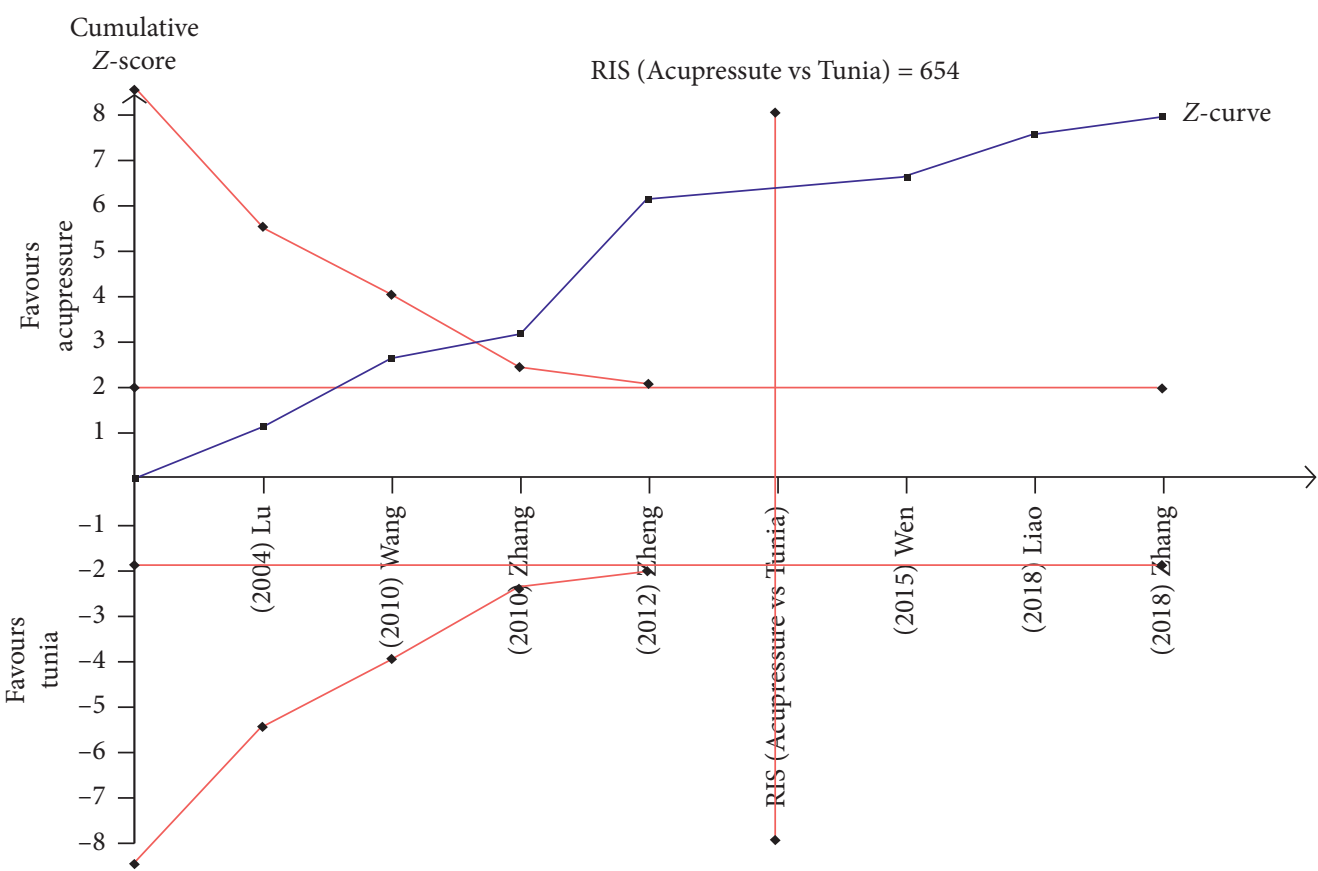

(a)

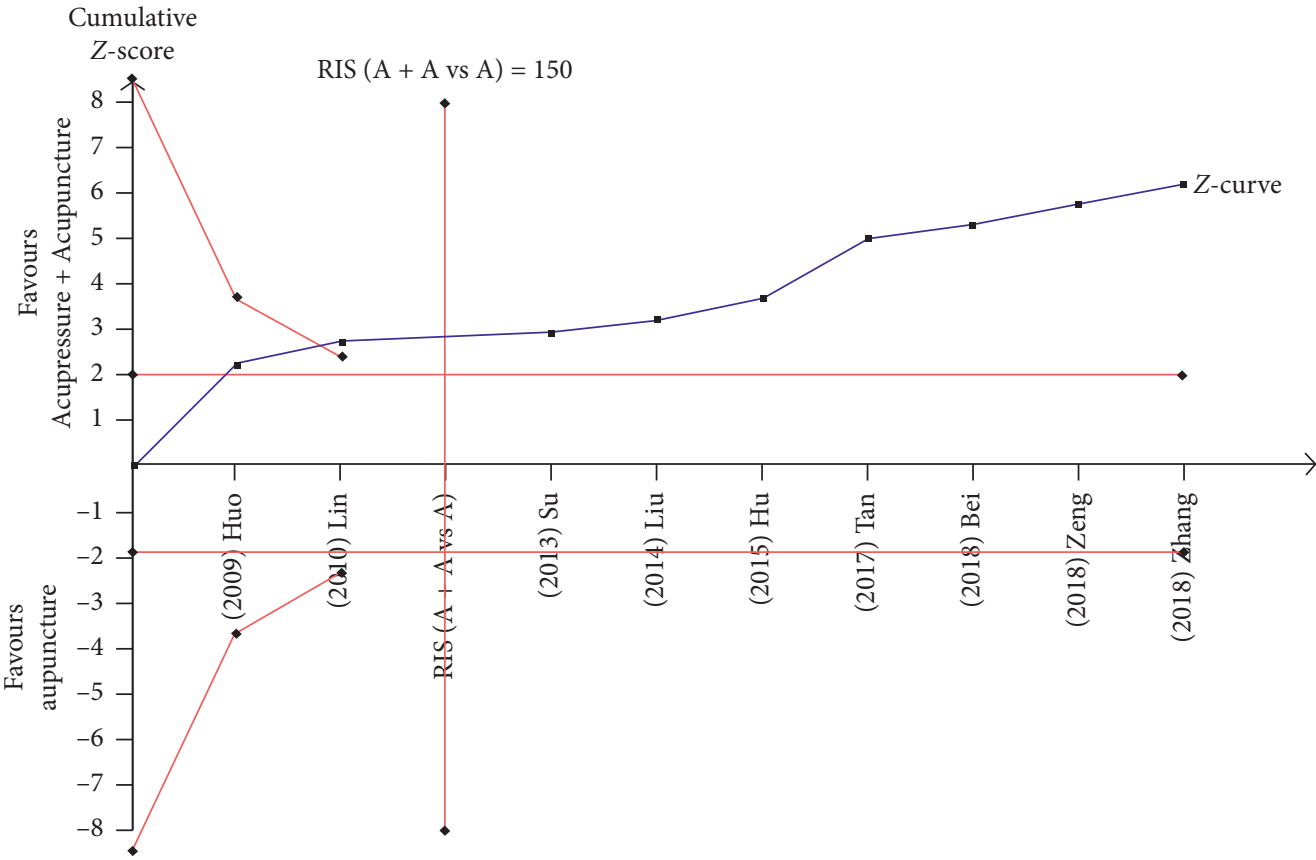

(b)

FIGURE 13: Trial sequential analysis on response rate comparing acupressure versus tuina massage and acupressure + acupuncture versus acupuncture.

strength, angle, and duration of each movement, as well as details of the treatments, such as frequency and duration of the treatment, might result in the heterogeneity found in our analysis. Recording these details could improve assessments of the effectiveness of acupressure, but few studies have collected such information.

Sparse and mild adverse events were reported in the RCTs, consistent with findings in the previous reviews $[6,40,44]$. However, the unclear methodological protocols for assessing adverse events, the unclear predictors of these events, and the limited number of RCTs reporting them contribute to a low overall apparent incidence of adverse events. Therefore, therapists need to fully inform patients of the potential risks of adverse events and to pay close attention to their potential occurrence.

The most important limitation in this systematic review was the limited number of studies with a low risk of bias. Only 5 eligible RCTs (22\%) were rated as low risk of bias in 
TABLE 3: GRADE summary of finding.

\begin{tabular}{|c|c|c|c|c|c|c|}
\hline \multirow[b]{2}{*}{ Interventions } & \multirow[b]{2}{*}{ Outcomes } & \multicolumn{2}{|c|}{ Illustrative comparative risks $(95 \% \mathrm{CI})$} & \multirow{2}{*}{$\begin{array}{c}\text { Relative } \\
\text { effect } \\
(95 \% \mathrm{CI})\end{array}$} & \multirow{2}{*}{$\begin{array}{l}\text { Number of } \\
\text { participants } \\
\text { (studies) }\end{array}$} & \multirow{2}{*}{$\begin{array}{c}\text { Quality of the } \\
\text { evidence } \\
\text { (GRADE) }\end{array}$} \\
\hline & & $\begin{array}{l}\text { Assumed risk } \\
\text { (control group) }\end{array}$ & $\begin{array}{l}\text { Corresponding risk } \\
\text { (test group) }\end{array}$ & & & \\
\hline \multirow[b]{2}{*}{$\begin{array}{l}\text { Acupressure versus tuina } \\
\text { massage }\end{array}$} & $\begin{array}{l}\text { Response } \\
\text { rate }\end{array}$ & 743 per 1000 & 928 per 1000 (862 to 1000$)$ & $\begin{array}{l}\text { RR } 1.25 \\
(1.16 \text { to } \\
1.35)\end{array}$ & 491 (5 studies) & $\oplus \oplus \Theta$ low $^{\mathrm{a}, \mathrm{b}}$ \\
\hline & VAS & $\begin{array}{l}\text { The mean visual } \\
\text { analog scale in the } \\
\text { control groups } \\
\text { was } 4.3275 \text { points }\end{array}$ & $\begin{array}{l}\text { The mean VAS in the } \\
\text { intervention groups was } \\
\mathbf{1 . 9 4} \text { standard deviations } \\
\text { lower }(0.78 \text { to } 3.11 \text { lower })\end{array}$ & & 663 (4 studies) & $\begin{array}{c}\oplus \odot \Theta \Theta \text { very } \\
\text { low }^{\text {a,b,c }}\end{array}$ \\
\hline $\begin{array}{l}\text { Acupressure versus physical } \\
\text { therapy }\end{array}$ & VAS & $\begin{array}{l}\text { The mean visual } \\
\text { analog scale in the } \\
\text { control groups } \\
\text { was } \mathbf{5 . 1 7 6} \text { points }\end{array}$ & $\begin{array}{l}\text { The mean VAS in the } \\
\text { intervention groups was } \\
\mathbf{0 . 8 8} \text { standard deviations } \\
\text { lower (1.10 to } 0.65 \text { lower) }\end{array}$ & & 335 (3 studies) & $\begin{array}{c}\oplus \oplus \oplus \ominus \\
\text { moderate }^{\mathrm{d}}\end{array}$ \\
\hline \multirow{2}{*}{ Acupressure versus usual care } & VAS & $\begin{array}{l}\text { The mean visual } \\
\text { analog scale in the } \\
\text { control groups } \\
\text { was } 4.97 \text { points }\end{array}$ & $\begin{array}{l}\text { The mean VAS in the } \\
\text { intervention groups was } \\
\text { 0.32 standard deviations } \\
\text { lower }(0.02 \text { to } 0.61 \text { lower })\end{array}$ & & 180 (2 studies) & $\oplus \oplus \Theta \Theta$ low $^{\mathrm{c}, \mathrm{d}}$ \\
\hline & ODI & $\begin{array}{l}\text { The mean ODI in } \\
\text { the control } \\
\text { groups was } \\
\mathbf{1 5 . 7 0 5} \text { points }\end{array}$ & $\begin{array}{l}\text { The mean ODI in the } \\
\text { intervention groups was } \\
0.55 \text { standard deviations } \\
\text { lower }(0.25 \text { to } 0.84 \text { lower })\end{array}$ & & 180 (2 studies) & $\oplus \oplus \Theta \Theta$ low $^{\mathrm{c}, \mathrm{d}}$ \\
\hline $\begin{array}{l}\text { Acupressure + acupuncture } \\
\text { versus acupuncture }\end{array}$ & $\begin{array}{l}\text { Response } \\
\text { rate }\end{array}$ & 772 per 1000 & 919 per 1000 ( 873 to 973$)$ & $\begin{array}{c}\text { RR } 1.19 \\
(1.13 \text { to } \\
1.26) \\
\end{array}$ & 720 (9 studies) & $\oplus \oplus \ominus \ominus$ low $^{\mathrm{a}, \mathrm{b}}$ \\
\hline \multirow{2}{*}{$\begin{array}{l}\text { Acupressure + acupuncture } \\
\text { versus acupuncture }\end{array}$} & VAS & $\begin{array}{c}\text { The mean VAS in } \\
\text { the control } \\
\text { groups was } 1.39 \\
\text { points }\end{array}$ & $\begin{array}{l}\text { The mean VAS in the } \\
\text { intervention groups was } \\
\mathbf{1 . 1 3} \text { standard deviations } \\
\text { lower }(0.94 \text { to } 1.31 \text { lower })\end{array}$ & & 530 (6 studies) & $\begin{array}{l}\oplus \Theta \Theta \Theta \text { very } \\
\text { low }^{\mathrm{a}, \mathrm{b}, \mathrm{c}}\end{array}$ \\
\hline & JOA & $\begin{array}{c}\text { The mean JOA in } \\
\text { the control } \\
\text { groups was } \\
\mathbf{1 9 . 0 9 5} \text { points }\end{array}$ & $\begin{array}{l}\text { The mean JOA in the } \\
\text { intervention groups was } \\
1.14 \text { standard deviations } \\
\text { higher ( } 0.94 \text { to } 1.34 \text { higher) }\end{array}$ & & 470 (6 studies) & $\begin{array}{l}\oplus \Theta \Theta \Theta \text { very } \\
\text { low }^{\text {a,b,c }}\end{array}$ \\
\hline
\end{tabular}

Note: (1) The basis for the assumed risk (e.g., the median control group risk across studies) is provided in footnotes. The corresponding risk (and its $95 \%$ confidence interval) is based on the assumed risk in the comparison group and the relative effect of the intervention (and its 95\% CI). (2) GRADE Working Group grades of evidence: high quality: further research is very unlikely to change our confidence in the estimate of effect; moderate quality: further research is likely to have an important impact on our confidence in the estimate of effect and may change the estimate; low quality: further research is very likely to have an important impact on our confidence in the estimate of effect and is likely to change the estimate; very low quality: we are very uncertain about the estimate. (3) a: randomization and blinding are not adequate or appropriate; b: high heterogeneity; c: confidence intervals are too wide; d: insufficient sample size.

the overall assessment. Most of the studies included in this review were evaluated as "high" or "unclear" risk of bias. We did not conduct a funnel plot and Egger's test to detect publication bias since there were fewer than 10 studies in each comparison.

Although analysis of combinative MA and EA individually suggested that each was superior to acupuncture alone, the combinative therapies that included acupressure combined with acupuncture in test groups had high heterogeneity, making it difficult to determine the efficacy of acupressure. The outcome measures could have had high heterogeneity because most of the RCTs used patient-reported scales or questionnaires, which could be influenced by memory or emotional bias, undermining the reliability of the results. Moreover, there is no study investigating the effectiveness of acupressure on acute low back pain. Most studies included patients with chronic low back pain, and no clear distinction of patients' histories was made in the remaining studies.

\section{Conclusion}

We demonstrated that acupressure could provide clinical benefits to LBP conditions and had a significant short-term response rate in LBP management. However, the overall reliability of this conclusion is limited by the methodological quality of the included trials. Better designed large-scale RCTs using reliable quantitative methods are necessary to confirm the efficacy of acupressure for LBP.

\section{Data Availability}

The data supporting this systematic review are from previous studies and datasets, which have been cited. The processed data are available from the corresponding author upon request. 


\section{Disclosure}

The funding bodies play no role in the design of the study and collection, analysis, and interpretation of data and in writing the manuscript.

\section{Conflicts of Interest}

The authors declare that they have no conflicts of interest.

\section{Acknowledgments}

This work was supported by the National Natural Sciences Foundation of China (No. 81874511).

\section{Supplementary Materials}

Supplementary file 1: searching strategy for each database used in this review. Supplementary file 2: PRISMA checklist. (Supplementary Materials)

\section{References}

[1] J. Hartvigsen, M. J. Hancock, A. Kongsted et al., "What low back pain is and why we need to pay attention," The Lancet, vol. 391, no. 10137, pp. 2356-2367, 2018.

[2] J. L. Dieleman, R. Baral, M. Birger et al., "US spending on personal health care and public health," JAMA-Journal of the American Medical Association, vol. 316, no. 24, pp. 26272646, 2016.

[3] C. Maher, M. Underwood, and R. Buchbinder, "Non-specific low back pain," The Lancet, vol. 389, no. 10070, pp. 736-747, 2017.

[4] N. E. Foster, J. R. Anema, D. Cherkin et al., "Prevention and treatment of low back pain: evidence, challenges, and promising directions," The Lancet, vol. 391, no. 10137, pp. 2368-2383, 2018.

[5] L. H. Yang, P. B. Duan, Q. M. Hou et al., "Efficacy of auricular acupressure for chronic low back pain: a systematic review and meta-analysis of randomized controlled trials," Evid Based Complement Alternat Med, vol. 2017, Article ID 6383649, 14 pages, 2017.

[6] N. Robinson, A. Lorenc, and X. Liao, "The evidence for Shiatsu: a systematic review of Shiatsu and acupressure," BMC Complement Altern Med, vol. 11, p. 88, 2011.

[7] B. H. Fan, Tuina, China Press of Tradtional Chinese Medicine, Beijing, China, 2015.

[8] H.-M. Chen, H.-H. Wang, M.-H. Chiu, and H.-M. Hu, "Effects of acupressure on menstrual distress and low back pain in dysmenorrheic young adult women: an experimental study," Pain Management Nursing, vol. 16, no. 3, pp. 188-197, 2015.

[9] M. Yeganeh, H. R. Baradaran, M. Qorbani, Y. Moradi, and S. Dastgiri, "The effectiveness of acupuncture, acupressure and chiropractic interventions on treatment of chronic nonspecific low back pain in Iran: a systematic review and meta-analysis," Complementary Therapies in Clinical Practice, vol. 27, pp. 11-18, 2017.

[10] Y.-W. Chen and H.-H. Wang, "The effectiveness of acupressure on relieving pain: a systematic review," Pain Management Nursing, vol. 15, no. 2, pp. 539-550, 2014.
[11] E. Godley and M. A. Smith, "Efficacy of acupressure for chronic low back pain: a systematic review," Complementary Therapies in Clinical Practice, vol. 39, p. 101146, 2020.

[12] B. Hutton, G. Salanti, D. M. Caldwell et al., "The PRISMA extension statement for reporting of systematic reviews incorporating network meta-analyses of health care interventions: checklist and explanations," Annals of Internal Medicine, vol. 162, no. 11, pp. 777-784, 2015.

[13] M. AnttiC. Roger et al., "Updated method guideline for systematic reviews in the cochrane back and neck group," Spine, vol. 40, no. 21, 2015.

[14] H. Balshem, M. Helfand, H. J. Schünemann et al., "GRADE guidelines: 3. Rating the quality of evidence," Journal of Clinical Epidemiology, vol. 64, no. 4, pp. 401-406, 2011.

[15] T. S. Zhang, W. S. Zhong, and B. Li, Applied Methodology of Evidence-Based Medicine, Central South University Press, Hunan, China, 2nd edition, 2014.

[16] J. Wetterslev, J. C. Jakobsen, and C. Gluud, “Trial Sequential Analysis in systematic reviews with meta-analysis," BMC Medical Research Methodology, vol. 17, no. 1, 2017.

[17] D. Kobayashi, T. Shimbo, H. Hayashi, and O. Takahashi, "Shiatsu for chronic lower back pain: randomized controlled study," Complementary Therapies in Medicine, vol. 45, pp. 33-37, 2019.

[18] L. L.-C. Hsieh, C.-H. Kuo, L. H. Lee, A. M.-F. Yen, K.-L. Chien, and T. H.-H. Chen, "Treatment of low back pain by acupressure and physical therapy: randomised controlled trial," BMJ, vol. 332, no. 7543, pp. 696-700, 2006.

[19] L. L.-C. Hsieh, C.-H. Kuo, M.-F. Yen, and T. H.-H. Chen, “A randomized controlled clinical trial for low back pain treated by acupressure and physical therapy," Preventive Medicine, vol. 39, no. 1, pp. 168-176, 2004.

[20] Y. X. Zhang, J. B. Liu, Y. H. Wang, J. Xu, and X. D. Bi, “Effect of acupressure based on meridian flow on lumbar disc herniation," China"s" Naturopathy, vol. 26, no. 06, pp. 31-32, 2018.

[21] Y. J. Zhang and P. F. Zhao, "Therapeutic effect of electric acupuncture combined with acupressure in patients with lumbar intervertebral disc protrusion," Clinical Research and Practice, vol. 3, no. 28, pp. 123-125, 2018.

[22] Z. H. Zeng and L. H. Pei, "Effect of acupressure and acupuncture on pain syndrome of patients with lumbar disc herniation," Journal of Sichuan of Traditional Chinese Medicine, vol. 36, no. 8, pp. 191-193, 2018.

[23] X. X. Liao, G. G. Feng, and Y. Q. Zhou, "Clinical effect of acupressure with syndrome differentiation of six meridians on lumbar disc herniation," China Modern Medicine, vol. 25, no. 28, pp. 155-157, 2018.

[24] X. Hua and J. W. Wang, "Clinical efficacy observation of acupoint massage combined with acupuncture in the treatment of lumbar disc herniation," Shanghai Journal of Traditional Chinese Medicine, vol. 52, no. 9, pp. 51-53, 2018.

[25] J. H. Bei, Z. M. Zhang, and R. Z. Chen, "Effect of electroacupuncture and jia's acupressure on postpartum low back pain," China's Naturopathy, vol. 26, no. 04, pp. 37-38, 2018.

[26] X. Zhang, C. W. Zhong, P. Zeng, and L. J. Wang, "Clinical observation on the third lumbar vertebra transverse process syndrome treated with tendon-relaxing and acupressure tuina," Jilin Journal of Chinese Medicine, vol. 37, no. 12, pp. 1269-1271, 2017.

[27] J. C. Tan, M. L. Xue, F. Y. He et al., "Effect of oblique acupuncture combined with acupressure on lumbar disc herniation," Journal of Practical Traditional Chinese Medicine, vol. 33, no. 11, 2017. 
[28] Y. H. Wen, "Clinical study on the treatment of lumbar disc herniation by acupressure of warming yang and dredging meridians," China Journal of Chinese Medicine, vol. 30, no. 9, Article ID 825966, 2015.

[29] Y. Hu, "Effect of acupressure and electroacupuncture on 40 cases of 40 cases of lumbar disc herniation," Journal of Clinical Acupuncture and Moxibustion, vol. 31, no. 12, pp. 22-24, 2015.

[30] C. K. Liu and Z. Zhang, "Effect of acupuncture combined with acupressure on lumbar disc herniation," Modern Journal of Integrated Traditional Chinese and Western Medicine, vol. 23, no. 1, pp. 36-37, 2014.

[31] X. Hua, W. D. Shen, and J. W. Wang, "Effect of acupressure and acupuncture on pain syndrome of patients with lumbar disc herniation," Shanghai Journal of Traditional Chinese Medicine, vol. 48, no. 11, pp. 59-61, 2014.

[32] D. J. Su, Effect of Electroacupuncture Combined with Meridian Acupressure for Lumbar Disc Herniation, Hubei University of Chinese Medicine, Wuhan, China, 2013.

[33] Z. J. Zheng, Q. Lin, Q. Zhou, Z. R. Chen, and W. W. Xu, "Clinical observation on pressure-sensitive points and massage traeatment for chronic lumbar disc herniation," Chinese Archives Of Traditional Chinese Medicine, vol. 30, no. 07, pp. 1565-1567, 2012.

[34] D. Zhang. Clinical, "Research on ran's yiqitongjing acupressure on lumbar disc herniation," Chinese Archives Of Traditional Chinese Medicine, vol. 28, no. 8, Article ID 2010417376, 2010.

[35] X. H. Lin, To Treat the Lumbar Intervertebral Disc Protrusion with the Combination of Pointing Therapy and Acupuncture, Guangzhou University of Chinese Medicine, Guangzhou, China, 2010.

[36] G. C. Wang, "Effect of acupressure on 43 cases with disc herniation," China Practical Medicine, vol. 5, no. 19, pp. 228-229, 2010.

[37] Z. J. Huo and J. Guo, "Therapeutic effect of electroacupuncture and acupressure on lumbar disc herniation," Chinese Acupuncture \& Moxibustion, vol. S1, no. 29, pp. 35-36, 2009.

[38] M. Lu, D. M. Cao, Y. J. Zhao et al., "Efficacy of Yiqitongjing acupressure on lumbar disc herniation," Chinese Acupuncture \& Moxibustion, vol. 24, no. 1, Article ID 2003401445, 2004.

[39] J. M. Wang, Clinical Observation on Treatment of Lumbar Intervertebral Disc Protrusion with Blood Stasis Type, Fujian University of Traditional Chinese Medicine, Fuzhou, China, 2016.

[40] J. J. Gagnier, H. Oltean, M. W. van Tulder, B. M. Berman, C. Bombardier, and C. B. Robbins, "Herbal medicine for low back pain: a cochrane review," Spine (Phila $\mathrm{Pa}$ 1976), vol. 41, no. 2, pp. 116-133, 2016.

[41] M. T. Cabýoglu, N. Ergene, and U. Tan, "The mechanism of acupuncture and clinical applications," International Journal of Neuroscience, vol. 116, no. 2, pp. 115-125, 2006.

[42] S. Serçe, Ö. Ovayolu, L. Pirbudak, and N. Ovayolu, "The effect of acupressure on pain in cancer patients with bone metastasis: a nonrandomized controlled trial," Integrative Cancer Therapies, vol. 17, no. 3, pp. 728-736, 2018.

[43] S. Patil, S. Sen, M. Bral et al., "The role of acupuncture in pain management," Current Pain and Headache Reports, vol. 20, no. 4, p. 22, 2016.

[44] E. J. Lee and S. K. Frazier, "The efficacy of acupressure for symptom management: a systematic review," Journal of Pain and Symptom Management, vol. 42, no. 4, pp. 589-603, 2011. 